\title{
Commentary: Frameworks for long term conditions must take account of needs of frail older people
}

\author{
Adam Gordon honorary associate professor in medicine of older people ${ }^{12}$, David Oliver president \\ 13
}

${ }^{1}$ British Geriatrics Society, London, UK; ${ }^{2}$ Nottingham University Hospitals NHS Trust, Nottingham, UK; ${ }^{3}$ Royal Berkshire NHS Foundation Trust, Reading, UK

As the NHS struggles in the face of high attendances at emergency departments, Eaton and colleagues' reminder about the importance of a structured response to long term conditions is timely. ${ }^{1}$ The approaches presented go some way to providing a framework for service development, but they also seem beguilingly straightforward. We know that whole system change will not be easy and that getting care for older patients with frailty "right" is crucial to the sustainability of the NHS, as it is for other healthcare systems.

In the UK, older patients with frailty have the highest consultation rate in general practice and form the majority of acute hospital admissions. Frailty is defined as a syndrome of diminished strength, endurance, reduced physiological function, and increased vulnerability to deterioration. ${ }^{2}$ The health status of these older people, who often have complex disease and comorbidities, is defined by more than their diagnoses. Assessment of their health must include appraisal of medical, psychological, functional, social, and environmental issues.

Evidence based modes of working for older frail patients-for example, comprehensive geriatric assessment-emphasise multidisciplinary working and case management, ${ }^{3}$ where doctors are important but equal contributors to a team of health professionals. Dialogues that point to the tension between service development in primary and secondary care miss the fact that, for older patients with frailty, the most important consideration is that these act in continuum. ${ }^{4}$ Seamless sharing of information, assessment, and management plans across sectors requires review and reform of information governance frameworks and increased trust and communication between primary and secondary care.

The current focus on person centred care runs the risk of overemphasising independence and stigmatising dependence and interdependence-both of which are facts of life for many older patients. When carers are involved, relationship centred care should be the goal. Relationship centred care puts the focus on interactions between the patient, family, carers, and health and social care staff. Supporting these interactions is important for delivering effective healthcare. These concepts are increasingly accepted and used in gerontological nursing. ${ }^{5}$ They must also become part of the mainstream dialogue in medical and nursing care.

All doctors need to become competent in managing older patients with frailty. The European Union of Medical Specialists has agreed a curriculum for undergraduate teaching on ageing across 29 countries, but most UK medical schools fail to teach this in full. ${ }^{6}$ And although the competencies required to be a geriatrician are well defined, those required to equip all physicians and general practitioners, for example, to provide the comprehensive multidisciplinary care that Eaton and colleagues' described remain unclear. Attempts to further debate this in the Shape of Training Review have met opposition from medical specialists. ${ }^{7}$ An open discussion about what doctors need to know is required.

Competing interests: We have read and understood BMJ policy on declaration of interests and have no relevant interests to declare. Provenance and peer review: Commissioned; not externally peer reviewed.

Eaton S, Roberts S, Turner B. Delivering person centred care in long term conditions. BMJ 2014;350:h181

2 British Geriatrics Society. Fit for frailty. 2014. www.bgs.org.uk/index.php/fit-for-frailty. 3 Welsh TJ, Gordon AL, Gladman JR. Comprehensive geriatric assessment-a guide for the non-specialist. Int J Clin Pract 2014;68:290-3

4 Oliver D, Foot C, Humphries R. Making our health and care systems fit for an ageing population.King's Fund, 2014. www.kingsfund.org.uk/sites/files/k/field/field_document/ older-people-report-slides-catherine-foot-mar14.pdf.

5 Nolan M, Davies S, Brown J. Transitions in care homes: towards relationship-centred care using the "senses framework." Qual Ageing Older Adults 2006;7:5-14.

6 Oakley R, Pattinson J, Goldberg S, Daunt L, Samra R, Masud T, et al. Equipping tomorrow's doctors for the patients of today. Age Ageing 2014:43:442-7.

7 Fuller G, Simpson IA. "Modernising medical careers" to "shape of training"-how soon we forget. BMJ 2014;348:2865. 
(c) BMJ Publishing Group Ltd 2015 